\title{
SELF-EVALUATION MANDALAS - AN INNOVATIVE AND MOTIVATING TOOL IN DISTANCE LEARNING COURSES (RESULTS FROM THE VTT-PROJECT)
}

Peter Mazohl, University of Technology Vienna, Harald Makl, Pedagogical University College, Austria

\section{Introduction}

This paper refers to the ERASMUS+ Project 2017-1-ES01-KA201-038199 (School Education). The project aims to develop a toolbox to assist teachers to develop and create high quality distance learning courses.

The innovation in the project is the self-evaluation mandala. This is a newly developed tool used in distance learning courses and in blended learning.

\section{Competence as course requirements}

Competence-based learning is an approach to education that focuses on mastery (Lassnigg, 2017). Students must demonstrate the desired learning outcomes as central to the learning process. Competence-based uses a keyword: "I can". Learning and teaching is geared on competences in Europe. To define the taught competences is an initial and crucial step for teachers and should always be done before the teaching process. The students should be informed about the competences they have to develop during the learning before they start to learn.

\section{Self-evaluation as a motivation for learners}

Self-assessment involves students in evaluating their own work and learning progress. They can identify their skills gaps and missing knowledge as well as they can track their progress. McMillan and Hearn (2008) mentioned as early as in 2008 that self-assessment and selfevaluation are useful processes to motivate students. Self-evaluation is an element of active learning.

\section{Likert scale to measure the competence level}

Self-evaluation means "Looking at your progress, development and learning to determine what has improved and what areas still need improvement. Usually involves comparing a 'before' situation with a "current situation" (BusinessDictionary, 2018). Likert scales (McLeod, 2008) are used to measure attitudes, opinions, perceptions, and behaviours. The used levels do not represent equal intervals and do not represent absolute values. A Likert scale for self-evaluation (of competences) can be designed by several levels of agreement to a 
given question, like "I can explain something". The selected revel reflects a personal level of estimation, like "strongly agree". In the developed self-evaluation the process of selfjudgement is based more on "feelings" than on absolute values.

\section{Learning success evaluation by mandala comparison}

Self-evaluation is a promising method also for the evaluation of learning processes, especially in Livelong Learning. The comparison of the competences at the beginning of the learning with the current competences after finishing the learning process provides a valuable picture of the learning success. Evaluation of learning success can easily be done with different types of assessments, which normally is expressed in grades. But - learning success is more than grades - to find out how much you have learned is a motivation for learners to learn and strengthen their self-confidence. It must be taken into account that self-evaluation can be influenced by the maturity of the learners.

\section{Research questions}

The issues mentioned created the impact to the research questions and are widely answered in this paper. It focuses on the following two research questions:

- Is there a method to motivate educators to define the taught competences before the course creation?

- Does there exist a simple self-evaluation method to compare the competence before and after the course?

\section{Methodology}

To find answers to the research questions special courses (using active learning methods) have been developed, implemented, and evaluated. The courses were distance learning based and lasted for a period of four to six weeks. The expected learning outcomes were defined using the competency that should be developed by the learners during the learning process. The defined competencies followed the guideline of the European Commission and were expressed in terms of knowledge, skills, and behaviour.

\section{The development of the mandala - from the idea to the tool}

To express the competencies a depiction based on a half circle was developed and labelled with the three competence items. The heading defines the description of the competence. 


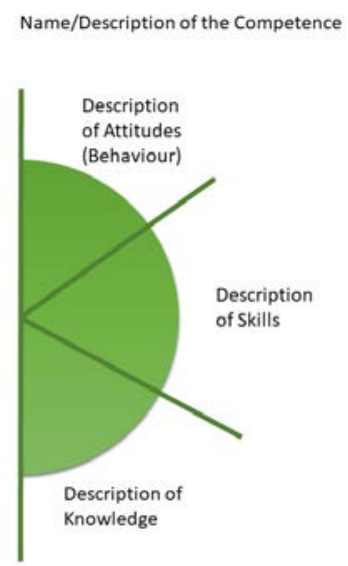

Figure 1. Basic considerations of the depiction (source: Peter Mazohl)

To offer the possibility to express the self-estimation in the three fields each field is split into four areas. These areas represent the various levels (worst level near the middle point of the half circle, best value in the area with the biggest distance of the middle point.

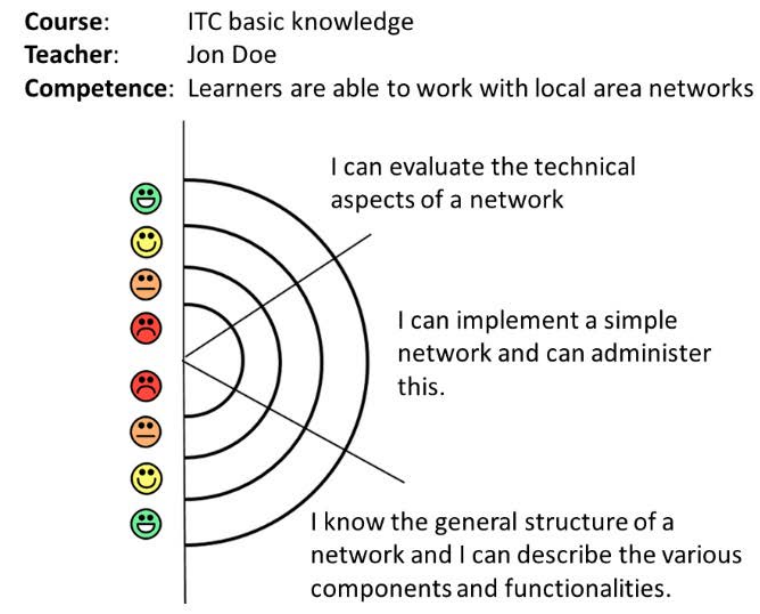

Figure 2. The mandala with four different levels for each part of the competence (source: Peter Mazohl)

In contrast to the classical levels of Likert based scale (which uses five levels) the neutral midlevel was dropped. With four levels, each learner must decide on a valuable level from the beginning. To comply with the educational field emoticons have been selected to express the level of agreement.

Before the course, the learners colour their estimated levels of each item of the competence. This can be done with several different methods:

- $\quad$ Printing the mandala, painting the selected areas with a pencil, taking an image with a smartphone, and finally uploading the image to the learning platform.

- Provision of the mandala in a digital format (for example an image in JPeG or PNG format) and the learners use an image editor to paint the selected areas. This needs 
digital competences (to download, save, to edit with an image processing or editing program, to save the mandala again, and finally to upload it to the learning platform).

After the course, the empty mandala is taken again and coloured by the learners. The difference between the two mandalas makes the learning success directly visible.
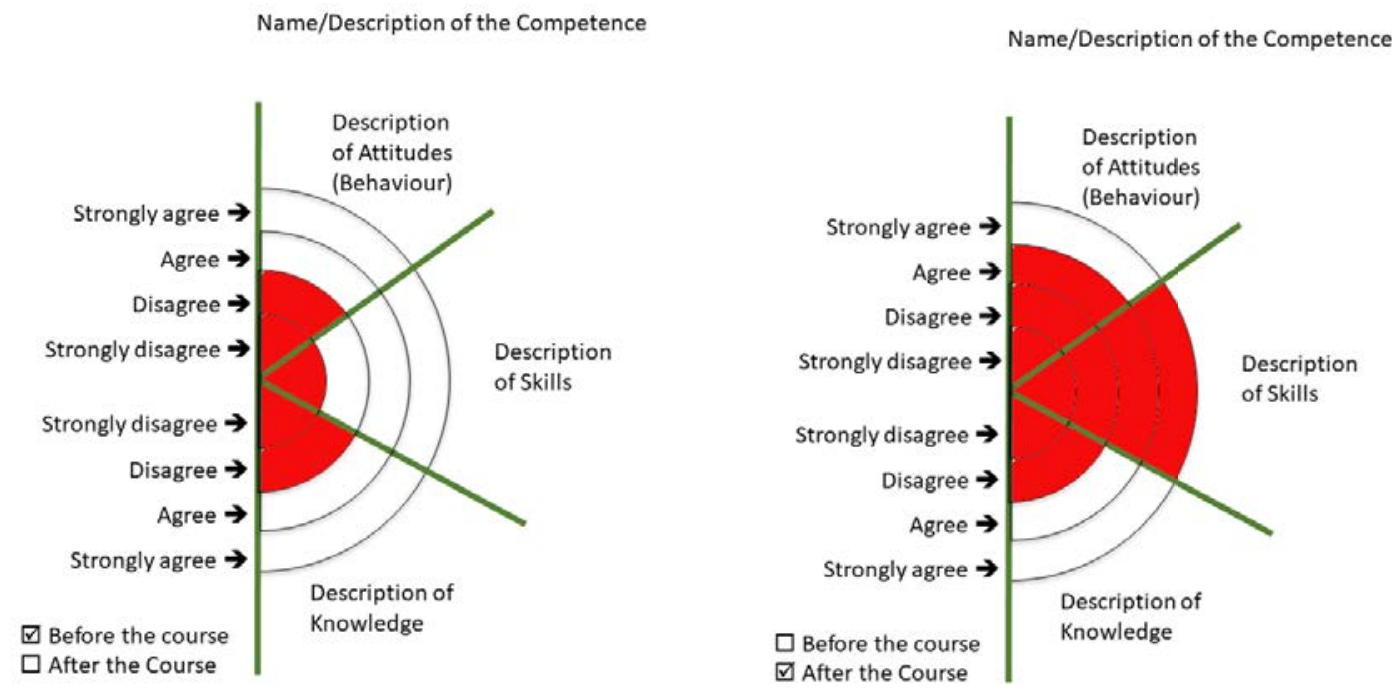

Figure 3. The painted mandala. Left: before the course; right: after the course. (source: Peter Mazohl)

This mandala has been taken from a proposal to implement the mandalas in Adult Education by replacing the emoticons by text.

\section{Course implementation}

In the frame of the Virtual Teacher Toolbox project (www.vtt-box.eu) several pilot courses have been developed to test the use of the mandala and to analyse the students' feedback. These courses are distance learning courses performed in school classes with 16 to 18 years old students in different subjects, like language, science, and arts teaching. The courses make intensive use of multimedia and interactive components to develop the required competences. This paper uses the results of the interviews of the course performed in a typical grammar school in Austria in the subject physics.

The course also used the frameworks developed in the frame of the project (pedagogy, quality, and digital competences).

\section{Course analyses}

Approximately 120 students were enrolled in the courses. 25 interviews are available (January 2019), the others will be interviewed after passing the courses within the next months. In the mentioned guided interviews students were asked seven basic questions with Likert based on two-level answers. Follow-up questions done individually completed the feedback of the students. 
Self-Evaluation Mandalas - An Innovative and Motivating Tool in Distance Learning Courses (Results from the VTT-Project)

Peter Mazohl, Harald Makl 
List of questions:

- Mandalas are an appropriate tool for the learning.

- The description of the competences in the mandala is a help for the learner.

- The Mandala itself is more fitting to younger students.

- The evaluation of the learners can be done by the teacher using the mandalas.

- An evaluation of the teacher's success in conveying the foreseen competences is possible.

- The mandala can be handled easily.

- The mandala offers a simple method to make the learning success by comparing the before and after mandala visible.

All students answered correctly to the questions with either "I agree" or "I disagree". Additionally, they could give specific comments, which were discussed between interviewer add students. A summary of the comments was used in the description of the results.

\section{Results}

The evaluation and analyses of the interviews was created as a simple yes/no bar chart.

\section{Experience with the Mandala}

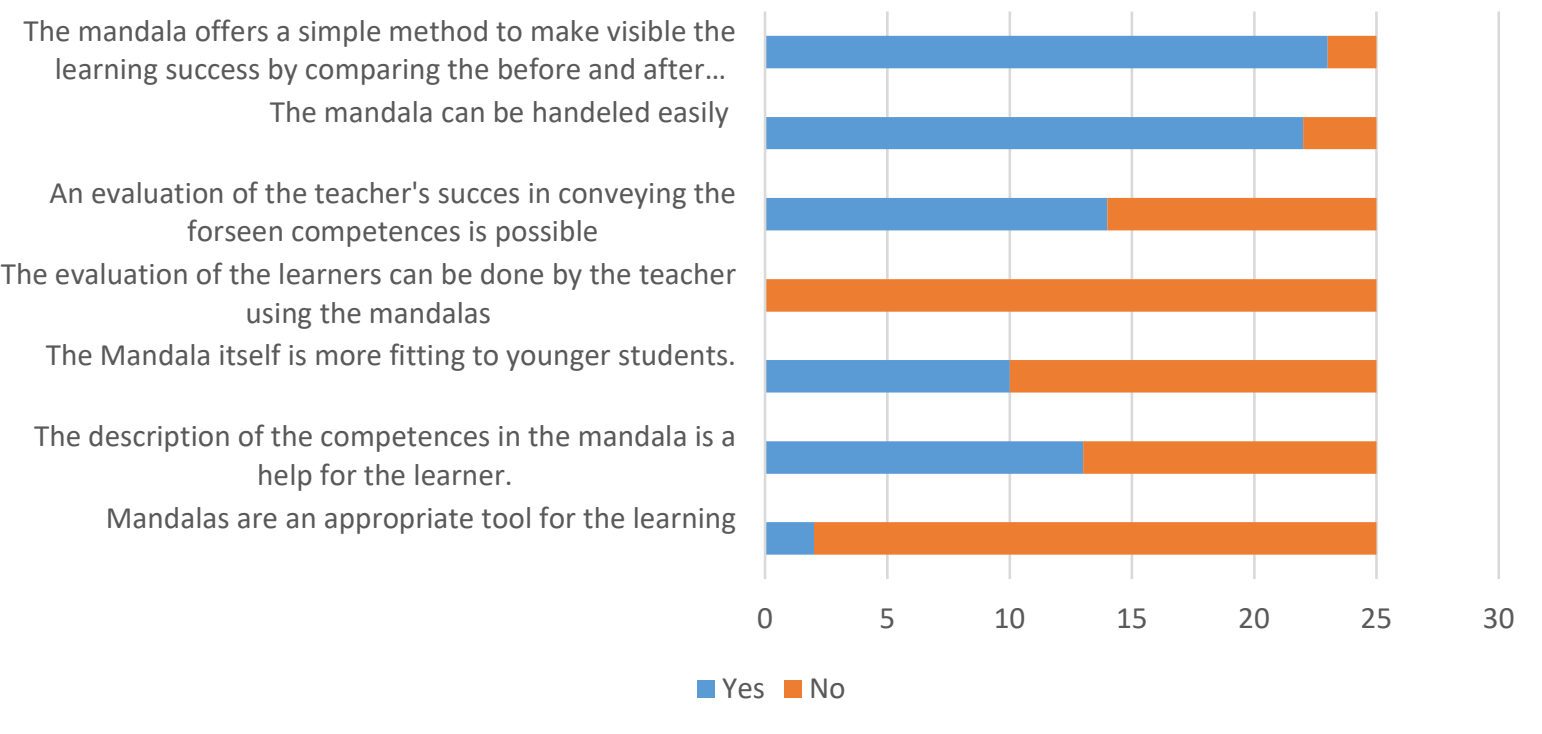

Figure 4. Overview of the answers given in the interview

The students gave individual statements to the various questions which are discussed as follows.

\section{Mandalas are an appropriate tool for the learning}

Students do not agree. The majority mentioned that the mandalas are more important to get an overview of the upcoming learning and the depiction provides some information about the expected learning outcomes (described in a competence). 
Self-Evaluation Mandalas - An Innovative and Motivating Tool in Distance Learning Courses (Results

from the VTT-Project)

Peter Mazohl, Harald Makl

\section{The description of the competences in the mandala is a help for the learner.}

Half of the students agree to this statement. The others were asked why they deny. They argued that they are learning in the frame of a curriculum. Therefore, the detailed information was not useful or important to them.

\section{The Mandala itself is more fitting to younger students.}

Several students meant that the painting job is "too childish for students". Nevertheless, a minority accepts the mandala as an appropriate tool for them.

\section{The evaluation of the learners can be done by the teacher using the mandalas}

Students don't want to be assessed by the mandala method, they prefer an assessment by the teacher. By the way, the students also mention the problem of maturity of learners. Younger students tend to cheat, especially if they know, that their self-estimation in the mandala is used to assess their learning or has an impact on their marks. They think it is not fair that students filling out the mandala honestly have a disadvantage compared with the cheating group.

\section{An evaluation of the teacher's success in conveying the foreseen competences is possible}

Students think that the mandala can be used to assess teachers work (under the pre-condition that students don't cheat in compiling the mandala). The comparison of the two mandalas of each student can be an appropriate means to find out what students have learned and how successful the teacher could teach the competences.

\section{The mandala can be handled easily}

The asked students think that the handling of the mandala is an easy job. This covers also the digital competences (download the mandala from the learning platform, use an image editor to paint the various areas with a specific colour, save the image and upload it to the learning platform).

\section{The mandala offers a simple method to make the learning success by comparing the before and after mandala visible}

Students agree that the learning success and the enhancement of the competences are made visible "by a glimpse". This is also motivating for the learners, because it is easy to realise the progress in enhancing competences. Another issue is the split of the competence into the three characteristic items and in any case, there was an enhancement for each single student minimum in one of the three parts. This obvious progress was mentioned as motivating for the learning. 


\section{Conclusion}

The feedback of a small group of 25 students gives a first overview of the use of self-evaluation mandalas.

In any case, the self-evaluation mandala forces the teacher (or trainer) to start with a very strict description of the taught competences and the expected learning outcomes in terms of competences. This definition can support students because they also know from the beginning which competence they must develop. The assessment of the students is also an issue - by the well-defined description of knowledge and skills they can prepare perfectly for any assessment.

Self-evaluation mandalas are easily suitable and represent a simple method in the course planning and development. Especially younger learners may appreciate the mandala as an informative tool to document their learning success. Nevertheless, other teacher-controlled objective assessment is necessary to evaluate the learning success (using formative as well as summative methods).

The self-evaluation mandala is an appropriate tool to compare the learning success of the students based on their self-estimation of their knowledge, skills and attitudes of a welldefined competence. The graphical depiction enables to recognize the learning success by a glimpse. In groups with a certain level of maturity the self-evaluation mandala - provided after the course - might be used as an item for the grading of students even if the feedback of the students to this topic was not so positive.

Finally, several remarks are necessary and must be discussed (and further researched in bigger samples and on various national bases is necessary):

- In which way does the maturity of the learner - especially the cheating of students play a role in using self-evaluation mandalas?

- It is necessary to find out to what extent the age of students plays a role in using the mandala seriously.

- The mandala method must be evaluated in other European countries to exclude typical national behaviour.

- The mandala could be transferred to Adult Education. It is recommended to run pilot courses with adults to find out the acceptance and the usability of the self-evaluation mandala. 
Self-Evaluation Mandalas - An Innovative and Motivating Tool in Distance Learning Courses (Results

from the VTT-Project)

Peter Mazohl, Harald Makl

\section{References}

BusinessDictionary (2018). What is self-evaluation? definition and meaning. Retrieved September 19, 2018, from http://www.businessdictionary.com/definition/selfevaluation.html

Digital Competence Framework: https://ec.europa.eu/jrc/en/digcomp/digital-competenceframework

Lassnigg, L. (2017). Competence-based Education and Educational Effectiveness. In M. Mulder (Ed.), Competence-based Vocational and Professional Education (vol., 23, pp. 667693). Cham: Springer International Publishing (Technical and Vocational Education and Training: Issues, Concerns and Prospects).

Mazohl, P., Ossiannilsson, E., Makl, H., Ampartzaki, M., \& Kalogiannakis, M. (2018). An Innovative Tool to Assist the Creation of High Quality Open, and Distance Learning Courses - The Virtual Teachers Toolbox (https://www.vtt-box.eu). In A. Szucs \& A. Volungeviciene (Eds.), Exploring the Micro, Meso and Macro. Navigating between dimensions in the digital learning landscape (pp. 550-556). EDEN 2018 Annual Conference. Genoa, 17 - 20 June. EDEN. Budapest, European Distance and E-Learning Network.

McLeod, S. A. (2008). Likert Scale | Simply Psychology. Retrieved September 19, 2018, from https://www.simplypsychology.org/likert-scale.html

McMillan, H. J., \& Hearn, J. (2008). Student Self-Assessment: The Key to Stronger Student Motivation and Higher Achievement on JSTOR. Educational Horizons, 87(1), 40-49. Online resource https://www.jstor.org/stable/42923742?seq=1\#metadata_info_tab_contents

Pedagogical Framework: https://www.vtt-box.eu/project/the-products/the-pedagogicalframework

Quality Framework: https://e-xcellencelabel.eadtu.eu

\section{Acknowledges}

The authors would like to express acknowledgements and thanks to the European Commission, who is co-funding the VTT-Box project (2017-1-ES01-KA201-038199), under the ERASMUS + KA2-Cooperation for innovation and the exchange of good practice, and KA201 - Strategic Partnership for School Education. The European Commission support for the production of this publication does not constitute an endorsement of the contents which reflects the views only of the authors, and the Commission cannot be held responsible for any use which may be made of the information contained therein.

The authors would like to express acknowledgements and thanks to all partners in the project. 